\section{Solução para remoção de lixo nas favelas: um projeto de estudo}

\author{
Szachna Eliasz Cynamon* \\ Teófilo Carlos do Nascimento Monteiro **
}

Slum areas in the way they present themselves result in human, social, and environment degradation. Each slum area demands its own and proper solution, but for each and every one slum area by itself the solution has to be a global one. Refuse is one of the problems which results in social, economical, sanitary and physical environment problems. The solution of the refuse problems has to be inserted in $a$ general solution, but admit a tentative step-by-step solution.

The authors analyse solutions which have been tryed by several agencies in Rio de Janeiro and finaly propose one more reliable tentative low cost solution, with the use of small refuse colection cans located in special joining points not far from the refuse production points. With special designed hand cars, the full cans are to be transported to assembly points where normal refuse collecting trucks may handle them.

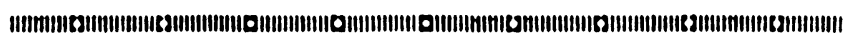

\section{INTRODUÇÃO}

No Rio de Janeiro existem atualmente 377 favelas, onde se concentram aproximadamente 1.800 .000 habitantes, representando $32 \%$ da população do município. $O$ número de favelas e a população favelada têm crescido progressivamente através dos anos, isto porque as favelas são a única opção de moradia para as populações de baixa renda. Como conseqüência desta situação, verifica-se nestas áreas a improvisação da ocupação, com as seguintes características: falta de traçado urbano, acessos irregulares e insuficientes, habitações de baixo padrão, inexistência ou precariedade de serviços públicos tais como: saneamento básico, escolas, postos de saúde, transportes etc., sendo extremamente difícil e cara a solução destes problemas por métodos clássicos convencionais.

\section{DIAGNOSTICO}

Neste contexto, o problema dos resíduos domésticos vem se agravando nas áreas carentes.

A dificuldade das companhias de limpeza urbana em recolher o lixo, devido ao traçado irregular dos arruamentos, dimensões incompatíveis com os equipamentos convencio-
* Escola Nacional de Saúde Pública - Fiocruz e Faculdade de Engenharia UERJ - Rio de Janeiro

** Escola Nacional de Saúde Pública - Fiocruz - Rio de Janeiro 
* Informação preliminar do estudo do Professor Jarbas Andrade da FIOCRUZ.

** Cynamon, S.E. Nota de aula das disciplinas de Saneamento e de Controle de Lixo. nais e a topografia irregular da região são razões para que o serviço de limpeza retire apenas cerca de $30 \%$ do lixo produzido nas favelas, apesar de diversas tentativas e do esforço em se desenvolver tecnologias alternativas para viabilizar a solução do problema do lixo nas favelas. ${ }^{2}, 5$.

A situação em que se encontram as populações tem como conseqüências:

- poluição visual do ambiente;

- acúmulo de lixo em grandes bolsões, causando a desestabilização de terrenos e estruturas existentes;

- contaminação do solo e das águas;

- entupimento de canais e redes de esgoto e de drenagem;

- obstrução do leito de rios causada por lançamento de lixo pelas populações de favelas situadas a suas margens, causando, em épocas de chuvas, a inundação da favela;

- proliferação de insetos, roedores e microorganismos patogênicos. ${ }^{4}$

Como ilustração, basta o exemplo da leptospirose, que, segundo pesquisa desenvolvida pela Fundação Oswaldo Cruz, infecta $60 \%$ dos ratos adultos capturados no Parque Carlos Chagas, uma favela do Rio de Janeiro.*

Várias tentativas têm sido feitas em busca de soluções para o problema. ${ }^{2,5}$.

De um lado, há as soluções espontâneas por parte das comunidades que se organizam em associações. Algumas tentativas bastante interessantes, apesar do desconhecimento técnico, escassez de recursos e descaso de grupos da própria coletividade. De outro lado, diversas entidades trabalham na pesquisa de soluções não-convencionais para a solução do problema.

A Fundação Oswaldo Cruz, através da Escola Nacional de Saúde Pública, cuja filosofia de ação para o problema é de um "Planejamento Global de Favela por Favela", no qual melhorias de saneamento devem ser inseridas, realiza estudos para a solução do problema do lixo em particular. ${ }^{* *}$

SOLUÇÕES ESTUDADAS POR DIVERSAS INSTITUIÇÕES QUE TRABALHAM COM FAVELAS NO RIO DE JANEIRO

- Sistema de coleta interna, organizado pela Associação de Moradores e apoio do Serviço Municipal de Limpeza, para retirada de "bolsões de lixo" acumulado nas favelas. Este sistema é feito através de mutirão, com utilização de equipamentos simples de propriedade dos próprios moradores, tais como: pás, vassouras, padiolas, carrinhos de mão, etc. $O$ sucesso deste tipo de solução depende da campanha educativa e promocio- 
nal que antecede ao evento e também da disponibilidade do Serviço de Limpeza em retirar regularmente o lixo coletado da comunidade.

Em resumo, esta solução é válida se após a retirada dos "bolsões de lixo" entrar em funcionamento um sistema regular de coleta que impeça um novo acúmulo de lixo.

- Colocação de caçambas do tipo "Dempter" nas ruas em que seja possível o trânsito do equipamento transportador.

Alguns problemas são verificados neste tipo de solução: - A distância do domicílio ao local da caçamba muitas vezes desestimula os moradores a levarem o lixo à caçamba, dando um destino impróprio ao mesmo; - A pequena capacidade ou a não retirada da caçamba pela companhia de limpeza na freqüência necessária faz com que o lixo transborde, sujando a rua e atraindo animais para seu interior.

- Execução de silos de lixo fixos representam o mesmo problema do caso anterior, agravado quando não se tem dispositivo de retirada automática do lixo.

- Rampas do tipo calha para descida do lixo até pontos de transferência usadas em favelas de terrenos íngremes. Requerem operação permanente.

- Veículos motorizados de dimensões menores, não convencionais, que têm um raio de ação maior, atingindo um número superior de ruas com coleta domiciliar, periódica. Resultados ainda não conclusivos.

- Utilização de incineradores nas comunidades: solução abandonada devido ao seu elevado custo de implantação e falta de recursos para manter o equipamento em funcionamento, causador de incêndios por operação indevida e de poluição atmosférica devida aos gases provenientes da queima de lixo.

- Deposição da matéria orgânica do lixo em biodigestores. Estudo ainda não conclusivo, mas certamente depende da solução do transporte.

\section{ALTERNATIVA, EM FASE DE ESTUDO, NA ESCOLA NACIONAL DE SAÚDE PÚBLICA}

a) Uso de latões de 2001 , (Fig. 1), colocados em locais estratégicos e em número suficiente de pontos que possibilitem pequenas distâncias a serem percorridas pelos moradores na remoção do lixo caseiro. (Fig. 2)

b) A retirada dos latões se faria pelos caminhões coletores comuns.

c) Em certas situações de favelas de morros ou mesmo favelas planas irregulares, propõe-se um pequeno carrinho de mão (Figs. 3 e 4), especialmente desenhado 
Latão de lixo com capacidade de 2001.

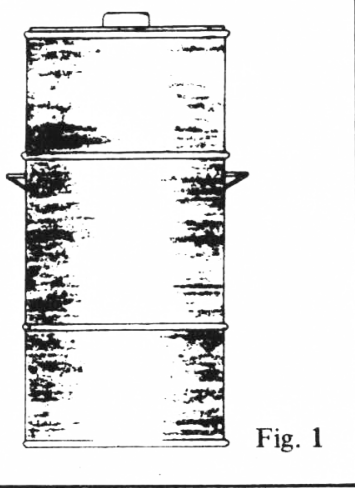

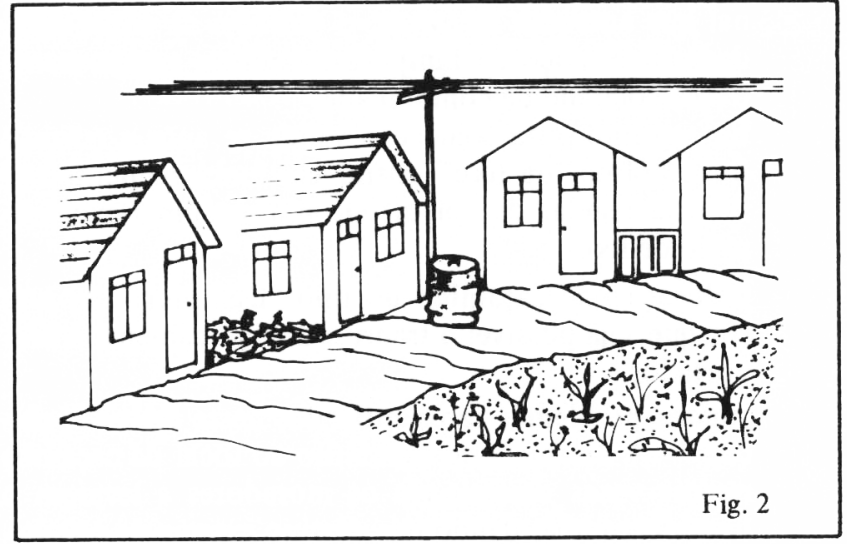

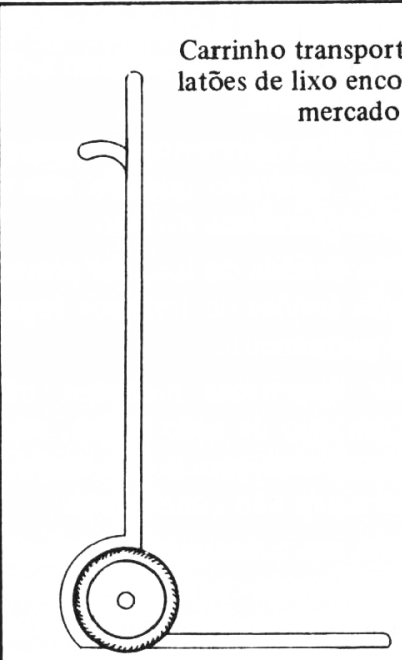

Fig. 3

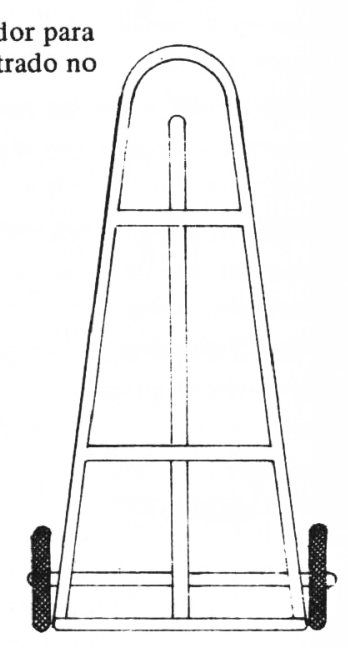

Fig. 4

para o transporte dos latões, que pode ser inclusive guiado através de degraus de escada até o ponto onde deve ser deixado para aguardar a coleta do caminhão. (Figs. 5 e 6).

d) Sistema de transporte dos latões, por meio da transformação do teleférico atualmente em uso experimental, quando não for viável a descida do latão por meio do carrinho de mão.

e) Campanha educativa para que a população faça a separação prévia do lixo dos utensílios recuperáveis na própria favela, tendo como estímulo o ingresso resultante da venda dos produtos recolhidos ou de produtos artesanais produzidos com os materiais separados. Para qualquer sistema a ser implantado é necessário entendimento com a comunidade para saber quais são 


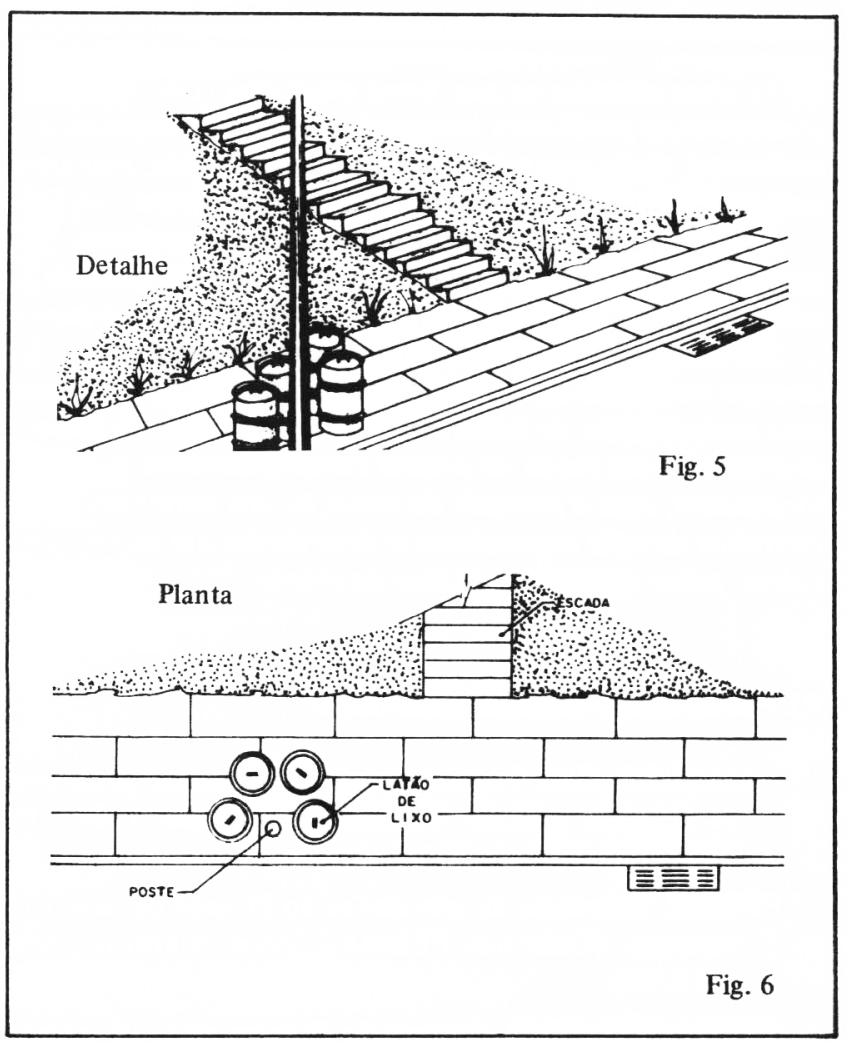

suas prioridades, seus desejos, o modo de se viabilizar o projeto e, ainda, promover campanhas educativas esclarecendo a importância do saneamento básico e de cada ação em particular. *

Os seguintes dados fazem parte do projeto:

- Produção diária de lixo:

- $0,3 \mathrm{Kg} / \mathrm{hab}$. dia

$1,5 \mathrm{Kg} /$ Família média dia

- volume produzido 6 1/Família

- Capacidade do latão proposto $2001=0,200 \mathrm{~m}^{3}$

- Famílias atendidas por latão 30-33 famílias - caso de retirada diária.

- Distâncias máximas aconselhadas da casa ao latão de armazenamento:

1 - Favelas planas $300 \mathrm{~m}$ preferência $200 \mathrm{~m}$

2 - Favelas de morro $150 \mathrm{~m}$ a $100 \mathrm{~m}$

- Previsão de latões:

1 - No caso de coleta diária - 2 jogos

2 - No caso de coleta em dias alternados -3 jogos

- Peso do lixo de um latão $50-60 \mathrm{Kg}$

- Peso do latão $8 \mathrm{Kg}$

- Peso do carrinho $14 \mathrm{Kg}$
Carro de mão transportando o latão de lixo

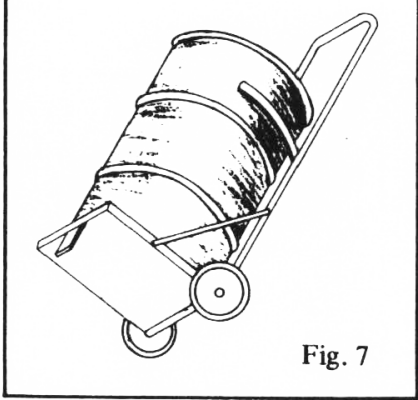

* Cynamon, S.E. Nota de aula das disciplinas de Saneamento $e$ de Controle de Lixo. 


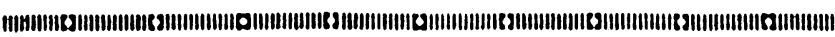

As áreas carentes na sua forma atual têm como conseqüência problemas humanos, sociais e de degradação ambiental. Cada área requer uma solução própria, mas para cada área favelada é necessário uma solução global.

$O$ lixo constitui-se num problema social, econômico, sanitário e ambiental. $A$ solução do lixo deve ser inserida numa solução geral, mas admite uma solução passo a passo.

São analisadas as soluções que foram tentadas por diversas entidades do Rio de Janeiro e, finalmente, proposta uma mais realista, de baixo custo, através do uso de latões distribuidos em locais de coletas estrategicamente localizados, com a previsão de remoção dos latões por carrinhos de mão especialmente desenhados até pontos de coleta, pelos caminhões de lixo da cidade.

\section{REFERENCIAS BIBLIOGRÁFICAS}

1. CAMARGO, H.S. Populações de baixa renda; problemas de limpeza pública COMLURB. Agosto/1981. (Publicação interna da Comlurb).

2. FEEMA. Relatório de atividades do Projeto de desenvolvimento. (Cadernos FEEMA - série relatórios técni$\cos 6 / 80)$.

3. FUNDAÇÃO SESP. Manual de Saneamento. 2a edição. Rio de Janeiro, 19.75.

4. GOLDBERG, N.R. et alii. Relatórios preliminares das condições gerais de saneamento básico da favela do Amorim. Rio de Janeiro, ENSP. Dep. de Saneamento, 1982.

5. SOUZA, C.S.M. Integração da favela ao sistema de limpeza urbana do município do Rio de Janeiro. Nov./ 1981. Rio de Janeiro, FEEMA, 1983. (Série Congressos). 